\section{AB0425 TREATMENT OF PATIENTS WITH RHEUMATOID ARTHRITIS IN POLAND - ESTIMATE THE FREQUENCY OF USE OF METHOTREXATE DURING A RANDOM APPOINTMENT WITH A RHEUMATOLOGIST}

\author{
K. Sikorska-Siudek ${ }^{1}$, M. Przygodzkaa ${ }^{1}$, R. Radomski ${ }^{2}$, S. Bojanowski ${ }^{2}$. \\ ${ }^{1}$ Mazovian Centre of Rheumatology and Osteoporosis; ${ }^{2}$ iEHR.eu, Warsaw, \\ Poland
}

Background: In accordance with the EULAR/ACR reomendations diseasemodifying antirheumatic drugs (DMARDs), particulary metotrexate (Mtx) should be applied after diagnosis of rheumatoid arthritis (RA). The goal of the treatment is to get remission/low disease activity

Objectives: The aim of this study was evaluation of the RA treatment, the frequency of use of Mtx and its dose application during control visits to rheumatologist in Poland. The disease activity was evaluated by using disease activity 28 joint score (DAS-28).

Results: There were analysed 301 case records of patients diagnosed with RA on the basis of the ACR 1997 and/or ACR/EULAR 2010 criteria. Patients recently diagnosed were excluded from analysis. In the examined group were 226 women and 75 men, median age 58.0, disease duration 5.0 Patients were divided in groups depending on the type of applied therapy $215(71 \%)$ patients were treated with Mtx monotherapy or combined with other DMARDs. 161 patients $(53 \%)$ took glucocorticosteroids simultaneously. Average DAS28 - 5.09, disease duration 6.2 At 18 patients $(6 \%)$ contraindications against the Mtx were stated. 127 patients (59\%) took high dosage of Mtx (20-30 mg/week), 84 (39\%) low dosage (7.5-15 mg /week) 31 patients (10\%) were treated other than Mtx DMARDs in monotherapy or in combined therapy $14(45 \%)$ took glucocorticosteroids simultaneously, average DAS $28-4.82$, disease duration $5.055(18 \%)$ patients didn't undergo treatment of DMARDs in the moment of analysis, 11 (20\%) patients underwent treatment with glucocorticosteroids. Duration of disease 2.1 average DAS 285,43

Conclusions: In patients treated with DMARDs in it also with Mtx a remission and/or a low activity of illness weren't being observed what is indicating for the ineffective treatment with RA.

Mtx wasn't applied in recommended doses in spite of the moderate or high activity of illness

There were patients who never had been treated with DMARDs. Causes of this occurrence require further research

Disclosure of Interest: None declared

DOI: 10.1136/annrheumdis-2017-eular.6773

\section{AB0426 THE EFFICACY OF THE TRIPLE COMBINATION THERAPY WITH METHOTREXATE, LEFLUNOMIDE AND METHYLPREDNISOLONE IN RHEUMATOID ARTHRITIS}

L. Groppa ${ }^{1}$, E. Russu ${ }^{1}$, L. Chislari ${ }^{1}$, O. Bujor ${ }^{2} .{ }^{1}$ Rheumatology and Nephrology, State University of Medicine and Pharmacy "Nicolae Testemitanu"; ${ }^{2}$ Arthrology, Republican Clinical Hospital, Chisinau, Moldova, Republic of

Background: The RA modern treatment approaches are based on "aggressive therapy", which aims at suppressing autoimmune inflammation and prevent joint destructionsat the early stages of the disease.

Objectives: To evaluate the effectiveness and tolerability of the triple combination therapy with methotrexate, leflunomide and methylprednisolone in patients with rheumatoid arthritis.

Methods: The study included 150 patients with rheumatoid arthritis. As a result of randomization, 50 patients received triple combination therapy (methotrexate +methylprednisolone+leflunomide), 50 patients with monotherapy with methotrexate, leflunomide 50 others. As a result all patient groups were comparable after all clinical and demographic indices.

Results: Our results showed that triple therapy is very effective in treating patients with RA. A significant improvement on the criteria of the AAR (ACR $>50)$ at the end of the study was observed in most patients receiving methotrexate, leflunomide and methylprednisolone. This is confirmed statistically and clinically positive dynamics significantly in almost all indicators used of efficacy (pain, stiffness, number of tender and swollen joints, the activity of AR, the value VSH index functional $\mathrm{HAQ}$ ) In addition, the use of triple therapy decreased average dose simultaneous use of glucocorticosteroids daily (from 5.0 to $2.5 \mathrm{mg}$ ) and $76 \%$ of patients canceled anti-inflammatory non-steroid drugs.

Conclusions: After randomized trial data lasting 24 months based triple therapy (methotrexate, leflunomide and methylprednisolone) was highly effective in patients with high RA activity. A significant improvement according to the criteria of ACR (ACR $>50)$ was obtained in 31 of 39 patients $(79.48 \%)$, including the nine patients $(23.07 \%)$ had developed clinical remission.

Administration of the basic triple therapy was characterized by a significant clinical effect ACR stability of $>50$. It was maintained during not less than 15 months of research in $28(90.32 \%)$ of patients who received this treatment and only 3 of $11(27.27 \%)$ patients who received methotrexate alone group and 8 in $10(80 \%)$ who administered $\operatorname{LF}(p=0.039)$. Evidence recovery $(A C R>50)$, as well as clinical remission was kept stable in all 28 patients that triple therapy was extended after the ending of basic research.

Disclosure of Interest: None declared

DOI: 10.1136/annrheumdis-2017-eular.6317

\section{AB0427 EFFICACY OF HYPNOTIC ANALGESIA FOR THE REDUCTION OF PAIN AND NEGATIVE EMOTIONAL STATES IN PATIENTS WITH RHEUMATOID ARTHRITIS OF THE "HOSPITAL CIVIL DE GUADALAJARA "FRAY ANTONIO ALCALDE"}

F. Bolaños-Chamorro ${ }^{1}$, L.A. Hernandez-Palma ${ }^{2}$, G. Vazquez-Murillo ${ }^{1}$, S. Cerpa-Cruz ${ }^{3}$, J.F. Muñoz-Valle ${ }^{2}$, R.M. Meda-Lara ${ }^{1}{ }^{1}$ Basic Psychology; ${ }^{2}$ Research Institute in Biomedical Sciences, University of Guadalajara; ${ }^{3}$ Division of Rheumatology, Guadalajara Civil Hospital Fray Antonio Alcalde, Guadalajara, Mexico

Background: Rheumatoid arthritis is a autoimmune and multisystemic disease. However, the negative emotions of anxiety and depression are the ones that have been most addressed, and there is a close relationship between pain associated with pain. Hypnosis is one of the best documented behavioral interventions in the management of acute and chronic pain in adults.

Objectives: To evaluate the efficacy of hypnotic analgesia for pain reduction and negative emotional states in patients with Rheumatoid Arthritis of the Guadalajara Civil Hospital Fray Antonio Alcalde

Methods: The method was developed through a quasi-experimental study, in which had two groups: a control group (CG) of 11 patients and an experimental group (EG) of 17, the women's age group were developed between 18 and 65 years old diagnosed with arthritis. The medition of Pain was realized through an instrument called EVA, and for the case of the Anxiety and depression were through HAD, achieving the baseline of each one of the variables. The EG group attended three psychological sessions of Hypnosis, with intervals of one month each. In these sessions, the perception of pain with an EVA was measured at the beginning and at the end. After a month, the subsequent evaluation was performed, measuring the same initial variables, in order to make the comparison of the pre and pos.

Results: The $U$ of MANN Whitney was applied and it was identified that in the pre-test measurement, there were no statistically significant differences in the variables. However, in the pos measurement, differences were found in the patient's pain perception $(z=-2.84, p<0.05)$, anxiety $(z=-2.36, p<0.05)$ and The depression $(z=-2.68, p<0.05)$. In addition, a Wilcoxon test was developed to determine differences between the pre-test score and the pos-test score in the EVA of each session. Statistically significant differences were found in the first session $(Z=-3.65, p=0.001)$, second session $(Z=-3.67, p=0.001)$ and third session $(\mathrm{Z}=-3.56, \mathrm{p}=0.001)$.

Conclusions: Hypnosis, as a behavioral technique, has shown efficacy in patients with chronic pain. In this research, a significant decrease in patients' perception of pain has been demonstrated.

References:

[1] Chopra, A. (2013). The COPCORD world of musculoskeletal pain and arthritis. Rheumatology (United Kingdom), 52(11), 1925-1928.

[2] Matcham, F., Rayner, L., Steer, S., \& Hotopf, M. (2013). The prevalence of depression in rheumatoid arthritis: A systematic review and meta-analysis. Rheumatology (United Kingdom), 52(12), 2136-2148.

Disclosure of Interest: None declared

DOI: 10.1136/annrheumdis-2017-eular.6983

\section{AB0428 A SYSTEMATIC REVIEW ON EFFICACY AND SAFETY OF SELECTIVE GLUCOCORTICOID RECEPTOR MODULATORS IN COMPARISON TO GLUCOCORTICOIDS IN ARTHRITIS}

M. Safy ${ }^{1}$, M.J. De Hair ${ }^{1}$, J.W. Jacobs ${ }^{1}$, F. Buttgereit ${ }^{2}$, M.C. Kraan ${ }^{3}$, J.M. van Laar ${ }^{1} .{ }^{1}$ Rheumatology and Clinical Immunology, University Medical Center Utrecht, Utrecht, Netherlands, ${ }^{2}$ Rheumatology and Clinical Immunology, Charité - Universitätsmedizin, Berlin, Germany; ${ }^{3}$ Department of Rheumatology and Inflammation Research, Institute of Medicine, University of Gothenburg, Gothenburg, Sweden

Background: Glucocorticoids (GCs) can cause unwanted effects. Both rheumatologists and patients classify osteoporosis, hyperglycemia/diabetes mellitus, cardiovascular diseases, and infections as the most worrisome adverse effects of GCs. Alternatives with less adverse effects but with good efficacy are needed, thus with a better efficacy/safety ratio. Selective GC receptor modulators (SGMRs) are designed to engage the receptor with dissociative characteristics: less transactivation of genes, mainly responsible for unwanted effects, while trans-repression of genes, inducing anti-inflammation, is maintained. Hereby, SGRMs are expected to have a better efficacy/safety ratio. A systematic review providing an overview of the efficacy and safety data of SGRMs is lacking.

Objectives: To systematically review the current literature on efficacy and safety of SGRMs in arthritis, compared to those of GCs.

Methods: A search was performed in Medline, Embase and the Cochrane Library, from inception dates of databases to October 5th, 2016. Experimental studies involving animal arthritis models or human material of arthritis patients, as well as clinical studies in patients of arthritis were included, if they reported original data. All types of arthritis were included. Data was extracted on the SGRM studied and on the GC as reference standard, design or setting of the study and whether or not safety and efficacy parameters had been reported.

Results: A total of 437 articles was retrieved of which 15 articles were eligible for our analysis. The following SGRMs were investigated: Compound $A^{1-6}$, PF-04171327 $7^{7}$ LGD-55528 ${ }^{8-9}$, Compounds $4^{10}, 5^{10}$, and $14^{11},(R)-16^{12},(R)-18^{13}$, 